\title{
PROMOÇÃO DO CONSUMO ALIMENTAR SUSTENTÁVEL NO CONTEXTO DA ALIMENTAÇÃO ESCOLAR
}

\author{
PROMOTION OF SUSTAINABLE FOOD CONSUMPTION IN THE CONTEXT OF MEALS AT SCHOOL \\ PROMOCIÓN DEL CONSUMO ALIMENTARIO SOSTENIBLE EN EL CONTEXTO DE LA ALIMENTACIÓN \\ ESCOLAR
}

Rozane Marcia Triches ${ }^{1}$

Resumo Este trabalho é sobre o consumo alimentar no contexto da alimentação escolar, entendendo-se esse espaço como fortemente propositivo na formação de hábitos alimentares saudáveis e de desenvolvimento sustentável. Relata o exemplo do município de Dois Irmãos, no Rio Grande do Sul, e as ações relativas ao trabalho realizado com os escolares, conjugando mudanças no consumo e na produção de alimentos e ligando saúde e sustentabilidade. Utiliza fontes secundárias e observação participante. A partir de diagnóstico preocupante sobre o estado alimentar e nutricional dessa população, diversas atividades de promoção do consumo alimentar sustentável foram desenvolvidas, entre elas: revisão dos fornecedores e das cadeias de abastecimento, das formas de produção e da qualidade dos alimentos oferecidos; regulação relativa ao tipo de gêneros trazidos de casa; cuidado na formulação dos cardápios; e desenvolvimento de atividades educativas práticas que coadunassem a melhora dos hábitos alimentares com a valorização do meio rural. Foram verificados, neste caso, exemplos de práticas inovadoras, desenvolvidas de forma integrada, que articularam sinergicamente educação alimentar e nutricional com ações para a consolidação de um sistema agroalimentar sustentável.

Palavras-chave educação alimentar e nutricional; consumo de alimentos; alimentação escolar; desenvolvimento; sustentabilidade.
Abstract This study is on food consumption in the context of meals provided at school, understanding this space as strongly proactive in forming healthy eating habits and encouraging sustainable development. It reports on the case of the municipality of Dois Irmãos, in the state of Rio Grande do Sul, Brazil, and the actions related to the work done with the students, combining changes in the consumption and production of food and linking health and sustainability with such changes. It uses secondary sources and participant observation. Based on the troubling diagnosis of the food and nutritional status of this population, several activities were developed to promote sustainable food consumption, including a review of the suppliers and supply chains, forms of production and quality of the food offered; regulation of the types of food brought from home; care in formulating menus, and development of practical educational activities that could blend the improvement of eating habits with greater appreciation for the rural area. In this case, a verification was made of examples of innovative practices, developed in an integrated manner, which coordinated food and nutrition education synergistically with actions aimed at the consolidation of a sustainable food system.

Keywords food and nutrition education; consumption of food; school meals; development; sustainability. 


\section{Introdução}

O termo 'sustentabilidade' tem se tornado recorrente diante dos problemas ambientais e suas múltiplas causas e inter-relações. Os modelos de desenvolvimento perseguidos, compostos por determinados padrões de produção e consumo de alimentos têm colaborado fortemente para o cenário existente. O modelo produtivista de produção de alimentos, amparado em tecnologias excludentes e poluentes e constituído por longas cadeias de abastecimento, ocasionou, em última análise, problemas sociais e ambientais, como o êxodo rural, a poluição, o aumento da produção de lixo, o empobrecimento do solo e a contaminação da água, entre outros (Lang e Heasman, 2004).

De outra parte, o consumo de alimentos tem se caracterizado pelo aumento considerável de produtos industrializados e pela diminuição do consumo de produtos básicos in natura, contrariando todos os guias e diretrizes de alimentação saudável dos órgãos de saúde pública. Da mesma forma, alimentos globalizados têm se tornado a cultura alimentar dominante, em detrimento da diversidade de culturas locais e tradicionais (Contreras, 2005).

A produção de alimentos baratos incentivou o seu acesso às populações com menor poder aquisitivo, mas também viabilizou dietas com má qualidade alimentar. Isso trouxe múltiplos malefícios à saúde que, conjugados às demais mudanças demográficas, econômicas e políticas, moldaram o cenário epidemiológico centrado em doenças crônicas não transmissíveis (Lang, Baling e Caraher, 2009). Portanto, além dos problemas de saúde pública, esse modelo de consumo incentivou o modelo de produção referido anteriormente e seus correspondentes efeitos ambientais.

Uma das proposições para mudar o panorama de saúde da população e o modelo de desenvolvimento tem destacado o papel do consumo e do consumidor. Ambos são considerados peças-chave na transformação ou manutenção desse cenário - afinal, podem não apenas gerar novos modelos, como também ser utilizados para manter o status quo pelos modelos dominantes. Ou seja, interessa transformar essa força dos consumidores de 'epistemologia da cegueira' para 'epistemologia da visão' (Freitas e Porto, 2011).

Diante dessas colocações, esse estudo ${ }^{2}$ se debruçou sobre a promoção do consumo alimentar no contexto da alimentação escolar, entendendo-a como fortemente propositiva na formação de cidadãos que promovam saúde não só para o corpo, mas também para o meio ambiente. Para tanto, toma como exemplo o município gaúcho de Dois Irmãos, no Rio Grande do Sul, e a forma como a administração municipal vem trabalhando a promoção do consumo alimentar sustentável com seus escolares. Não obstante, importa, antes mesmo de iniciar a análise deste caso, fazer algumas reflexões sobre a temática da educação alimentar e nutricional (EAN) aliada ao consumo sustentável. 


\section{Aliando educação alimentar e nutricional ao consumo sustentável}

Os debates sobre promoção da saúde e educação alimentar tomam lugar nas discussões sobre consumo sustentável, pois põem em destaque as ações do Estado diante de ambos os desafios. Santos ressalta que a promoção da saúde foi definida pela Carta de Ottawa como "o processo de capacitação da comunidade para atuar na melhoria da sua qualidade de vida e saúde, incluindo maior participação no controle deste processo" (Santos, 2005, p. 684). Nesse sentido, a elaboração e a implantação de políticas públicas saudáveis, a criação de ambientes favoráveis à saúde, o reforço da ação comunitária, o desenvolvimento de habilidades pessoais e a reorientação do sistema de saúde seriam os cinco principais campos de ação definidos na Carta de Ottawa (Santos, 2005).

Por sua vez, o Marco de Referência em Educação Alimentar e Nutricional para as Políticas Públicas, publicado pelo Ministério do Desenvolvimento Social em 2012, enfatiza que o conceito de educação alimentar e nutricional é um campo de conhecimento e de prática contínua e permanente, transdisciplinar, intersetorial e multiprofissional que visa promover a prática autônoma e voluntária de hábitos alimentares saudáveis (Brasil, 2012). Para tanto, o documento indica que a prática da EAN deve fazer uso de abordagens e recursos educacionais problematizadores e ativos que favoreçam o diálogo com indivíduos e grupos populacionais, considerando todas as fases do curso da vida, etapas do sistema alimentar e as interações e significados que compõem o comportamento alimentar.

Essa discussão é importante, pois a ideia deste estudo foi demonstrar que a educação alimentar e nutricional efetiva não pode situar-se apenas em ações e intervenções reducionistas de adestramento, como frequentemente se verifica empiricamente. Ela extrapola a educação formal e se insere no conjunto de práticas que moldam o ambiente no qual os indivíduos estão inseridos. Normalmente, verifica-se a ocorrência de atividades chamadas de 'educação alimentar e nutricional' que se resumem ao repasse de informações, seja via palestras, cursos ou material informativo, de forma pontual e restrita. Parte-se do pressuposto de que as pessoas são capazes de colocar esses discursos em prática e que são as únicas responsáveis por sua saúde e alimentação, e, portanto, também de sua doença. Esse tipo de intervenção tem demonstrado sua insuficiência ao partir do princípio único da necessidade de 'ensinar' as pessoas a se alimentarem corretamente, e não da premissa de que se deve questionar e modificar o meio em que se vive dado pela sua estrutura política e socioeconômica.

Desse raciocínio, conjuntamente com as discussões sobre o direito do consumidor e o direito humano à alimentação adequada, é que derivam as concepções de educação para o consumo. Trata-se de políticas específicas que preveem 
uma série de ações que buscam informar e orientar a população em geral via os meios de comunicação, escolas, empresas e na família para que o brasileiro passe a ter mais consciência na hora de escolher o que levar à mesa (Santos, 2005, p. 686).

Por sua vez, o consumo sustentável refere-se às práticas que encorajariam o desenvolvimento sustentável, interconectando as preocupações ambientais com as práticas de produção e consumo e suas consequências para as presentes e futuras gerações.

Para tanto, as políticas alimentares são centrais nessa mudança. O modelo econômico de livre mercado tem moldado as práticas alimentares, o consumo e o tipo de produtos que são oferecidos com a finalidade primordial do lucro. Não há, por parte da indústria alimentícia, a preocupação com a saúde da população, a não ser que a própria saúde se torne mercado lucrativo.

Concorda-se com Diez-Garcia (2012) que considera não ser possível atualmente deixar de dimensionar a influência da publicidade nas práticas alimentares. O que vem acontecendo é que a indústria alimentar movimenta altos recursos para investir em marketing e propaganda de seus produtos, enquanto o Estado não tem priorizado investimentos em promoção de saúde e medidas preventivas, embora se perceba, nos últimos anos, esforços governamentais na questão educacional. Exemplos disso são as estratégias de campanhas e controle das informações, além da atuação na normatização da comercialização dos alimentos, explicitando a busca de maior comprometimento ético da publicidade e da propaganda.

Dentre os esforços do Estado, destacam-se as políticas de segurança alimentar e nutricional e seus pressupostos na ampliação da importância da promoção da alimentação adequada (Cervato-Mancuso, Vieira e Costa, 2011). $\mathrm{O}$ marco de referência em EAN indica alguns princípios organizativos e doutrinários, dos quais se enfatizam a sustentabilidade social, ambiental e econômica, a abordagem do sistema alimentar, na sua integralidade, a valorização da cultura alimentar local e o respeito à diversidade de opiniões e perspectivas, e a educação enquanto processo permanente e gerador de autonomia e participação ativa e informada dos sujeitos. Já em 2004, Boog propunha quatro enfoques básicos para a educação nutricional voltada à segurança alimentar e nutricional sustentável (SAN): direito à alimentação, promoção da saúde, sustentabilidade ambiental e cuidado.

No que tange ao aspecto da sustentabilidade, considera-se que a EAN deve preocupar-se com as dimensões do desenvolvimento e dos padrões de produção, de abastecimento, de comercialização, de distribuição e de consumo de alimentos. Boog (2004) pontua que a preservação do meio ambiente e a não utilização de agrotóxicos e de produção extensiva em monoculturas estão atreladas à preservação da cultura alimentar e à valorização e manu- 
tenção da produção local. A adesão indiscriminada a produtos industrializados não compromete apenas a qualidade nutricional da alimentação, pois, quando práticas alimentares tradicionais cedem lugar a gêneros frequentemente menos saudáveis, mais ricos em gordura e geradores de lixo, compromete-se também a sustentabilidade. Além disso, para Boog, a aceitação do produto traz consigo a incorporação do complexo de valores e de condutas que se acham implicados nele. Assim, é importante que as pessoas façam escolhas conscientes, mas também que essas escolhas possam, por sua vez, interferir nas etapas anteriores do sistema alimentar (Brasil, 2012).

Portanto, segue-se que à educação nutricional compete oferecer subsídios aos cidadãos para que, em meio a escolhas, possam tomar decisões ativas e informadas. Nesse sentido, a EAN deve ampliar a sua abordagem para além da transmissão de conhecimento e gerar situações de reflexão sobre as situações cotidianas, adotando padrões alimentares sustentáveis e, sobretudo, éticos, isto é, que preservem a saúde, a cultura, o prazer de comer, a vida, os recursos naturais e a dignidade humana (Boog, 2004; Brasil, 2012).

Diante dessas perspectivas é que a alimentação escolar surge como importante ferramenta do Estado na promoção do consumo alimentar sustentável. Se considerarmos que o público-alvo são crianças (escolares) que geralmente não têm o poder de decisão e são influenciadas em suas escolhas de consumo, evidencia-se ainda mais a importância desse controle. Além disso, hábitos, comportamentos e preferências adquiridos na infância são mais facilmente mantidos até a idade adulta, criando padrões que se tornam resistentes à mudança. Portanto, a alimentação nos primeiros anos de vida traz consequências não só para a saúde atual e futura, mas também influencia na manutenção ou mudança de determinados sistemas alimentares.

No estudo de Morgan e Sonnino (2007) sobre os programas de alimentação escolar da Itália e do Reino Unido, os autores destacam que, em ambos os locais, o Serviço de Alimentação Escolar era utilizado para 'empoderar o consumidor'. Para tanto, as opções deveriam ser restritas, levando-se em consideração a premissa de que, para dar o poder da escolha, antes se deve dar o poder da informação. Por sua vez, essa informação não se reduzia a meras mensagens de promoção da saúde, mas constituía-se de aprendizado sobre a produção local e a cultura alimentar (Morgan e Sonnino, 2007 e 2008).

No Brasil, a recente lei n. 11.947/2009, que regulamenta o Programa Nacional de Alimentação Escolar, incorpora, em suas diretrizes, o desenvolvimento sustentável, fazendo alusão ao incentivo à promoção de consumo alimentar que respeite a cultura e a vocação agrícola local. Nesse contexto, importa dar visibilidade a experiências que concretizem essa retórica, verificando como elas a viabilizam. 


\section{O papel da alimentação escolar na promoção do consumo alimentar sustentável: o caso do município de Dois Irmãos}

Um dos valores do livre mercado é a liberdade de escolha, o quem nem sempre condiz com atitudes informadas e benéficas. No caso da alimentação escolar, como frisado anteriormente, o Estado tem importante papel, a partir de suas regulações, na condução e institucionalização de determinados tipos de comportamento. É com o objetivo de visualizar como essa intervenção estatal pode ser realizada que este estudo traz o caso do município de Dois Irmãos, no Rio Grande do Sul.

Dois Irmãos integra a Região Metropolitana de Porto Alegre, e está localizado a apenas $52 \mathrm{~km}$ da capital, na região nordeste do estado do Rio Grande do Sul. Conta com uma população de 25.572 habitantes em uma área de $65,16 \mathrm{~km}^{2}$, com densidade populacional de 423,2 hab $/ \mathrm{km}^{2}$, sendo o sétimo município mais urbanizado do estado no ano de 2000 (Instituto Brasileiro de Geografia e Estatística, 2011). O Produto Interno Bruto (PIB) per capita em 2008 foi de R\$19.571,00 (Instituto Brasileiro de Geografia e Estatística, 2010) e o Índice de Desenvolvimento Humano (IDH), segundo os dados de 2000 do Programa das Nações Unidas para o Desenvolvimento (Pnud), foi de 0,812 (Triches e Schneider, 2010). O município recebeu, em 2005, o Prêmio Gestor Eficiente da Merenda Escolar, na categoria Continuidade, pela organização não governamental (ONG) Fome Zero e pelo Ministério da Educação. O trabalho visando à alimentação escolar também levou o município a ser referência nacional e internacional, referência divulgada científica e midiaticamente pelo conjunto de inovações e permanência de suas ações.

Portanto, a descrição dessa experiência é importante no que tange à compreensão de quais trabalhos foram desenvolvidos e de que forma isso implicou a mudança não só no consumo e na saúde da população, mas também na produção e nos modelos de desenvolvimento. O período estudado corresponde aos anos de 2003 a 2010 e o estudo foi subsidiado por informações secundárias e observação participante.

Pretendendo ser didático e claro, este artigo se subdivide em diagnóstico, intervenções realizadas e resultados obtidos, seguindo certa linearidade. No que tange ao primeiro ponto, as preocupações com a alimentação escolar no município tornaram-se maiores a partir dos diagnósticos realizados em 2003-2004, os quais demonstraram um quadro alimentar e nutricional que atestava a tendência nutricional já observada no país: o aumento dos índices de sobrepeso associado a práticas alimentares caracterizadas pelo consumo de alimentos com alta densidade energética e industrializados em detrimento dos básicos e mais naturais.

A pesquisa realizada nos municípios de Dois Irmãos e Morro Reuter com escolares de 8 a 10 anos verificou que 17\% estavam acima do peso, que a 
obesidade estava fortemente associada a práticas alimentares menos saudáveis e que os conhecimentos sobre nutrição não eram suficientes para que essas crianças se conscientizassem e melhorassem suas práticas (Triches e Giugliani, 2005). Além disso, praticamente $70 \%$ destes mesmos escolares estavam insatisfeitos com seu corpo (Triches e Giugliani, 2007). Essas constatações levaram a concluir que o ambiente é decisivo na formação de hábitos alimentares e fundamental para modificar a alimentação e prevenir doenças.

Foi com esse diagnóstico que o Programa de Alimentação Escolar (PAE) do município começou a pensar em intervenções para a promoção do consumo alimentar sustentável, não de forma convencional, apelando para o convencimento racional a partir de educação formal e repasse de conhecimentos, mas sim iniciando pela revisão das questões de qualidade dos alimentos. O incentivo seria pela atratividade, remetendo primeiramente às questões organolépticas e culturais. Disso resultaram as motivações para repensar a procedência e os métodos de produção que propiciassem o provimento de alimentos mais frescos, naturais, tradicionais e saborosos e que conquistassem o paladar dos alunos para alimentos como frutas, verduras e gêneros menos processados, integrais e típicos da região (Triches e Schneider, 2010).

Essa necessidade levou a algumas práticas, como a introdução de alimentos locais provenientes da agricultura familiar, a implantação de horta municipal e hortas escolares com produção orgânica de hortaliças e frutas e a introdução de produtos integrais no cardápio. Essas atividades foram acompanhadas de práticas pedagógicas que pretendiam auxiliar nas mudanças alimentares e nutricionais no contexto da saúde e da sustentabilidade, como veremos a seguir.

O município de Dois Irmãos começou a adquirir produtos da agricultura familiar já em 2004, antecipando-se à lei n. 11.947/2009, que passou a exigir que todas as entidades executoras utilizassem no mínimo 30\% do recurso federal para aquisição de produtos desses fornecedores. Dentre as contribuições da prática, citam-se as mudanças nas concepções e práticas alimentares das crianças no que tange ao consumo de alimentos mais nutritivos e saudáveis, como frutas e hortaliças. Isso fica claro no depoimento das cozinheiras das escolas, que atestam a melhor qualidade, frequência e diversidade dos produtos, determinando maior aceitação e consumo por parte dos alunos. Além dos aspectos nutricionais, essa prática também interferiu na realimentação da cultura e do hábito regional, na medida em que passou a incentivar os paladares para alimentos produzidos localmente e a valorizá-los (Triches e Schneider, 2010).

Igualmente, torna-se importante destacar suas contribuições na construção de mercados para agricultores familiares locais e suas consequências, das quais são citadas as principais: a escolha por formas de plantio e 
produção diferenciadas, como os alimentos orgânicos e tradicionais, levando à promoção dessas estratégias; o incentivo à organização, à cooperação e à formalização; e a garantia da venda dos gêneros produzidos, com o aumento da renda e, provavelmente, diminuição do êxodo rural (Triches e Schneider, 2010).

Somam-se a esses elementos a questão ambiental e, com ela, a valorização de técnicas de produção 'amigas da natureza'. A título de exemplificação, o município de Dois Irmãos adquire o néctar de uva produzido a partir de uvas orgânicas, e extraído a vapor (Triches e Schneider, 2010). Segundo a nutricionista da alimentação escolar do município, além de a uva ser orgânica, o suco produzido pelo produtor daquele município distingue-se dos demais pela forma artesanal de extração do sumo, o que permite alto grau de resveratrol, substância associada à diminuição do colesterol e à prevenção de doenças cardiovasculares (Triches e Schneider, 2010). Mais do que isso, as embalagens utilizadas são de vidro e devolvidas para serem aproveitadas pelos agricultores, diminuindo a produção de lixo.

Outro fator diz respeito ao transporte. Ao favorecer cadeias curtas de abastecimento, ou seja, a compra direta dos produtos de agricultores locais, evita-se grande quantidade de uso de combustíveis e de emissão de gás carbônico, reduzindo-se as distâncias entre produção e consumo. Lang e Heasman (2004) defendem que a maior fonte de emissão de gases está relacionada ao abastecimento alimentar proveniente do transporte.

Assim, os diversos benefícios dessa prática foram fomentando outras mudanças. Salientando ainda mais a questão da tradição e da cultura alimentar local, incluíram-se na alimentação escolar produtos integrais que eram preparações típicas daquela região de colonização alemã, como o pão, a cuca, a rosca de polvilho, os bolos e os biscoitos. Outros gêneros também bastante utilizados passaram a ser integrais, como o arroz (que também era orgânico), o açúcar (mascavo), a granola, a mistura para bolo, as barras de cereal e o macarrão. A maior parte dos alimentos introduzidos, segundo análises de aceitabilidade e observação, foi bem aceita. Os alimentos com pouca aceitabilidade foram revistos de forma a diminuir a proporção de farinhas integrais, reformular a sua constituição, associar a outros alimentos bem aceitos ou foi reduzida a sua frequência no cardápio. Do mesmo modo, as próprias cozinheiras tiveram aulas de culinária integral para preparar alimentos de forma a agradar o paladar das crianças.

A prática de rever o cardápio e as aquisições públicas para a alimentação escolar foram complementadas com a produção própria de hortaliças e verduras orgânicas. Todas as unidades escolares municipais passaram a ser abastecidas com a totalidade desses gêneros produzidos na horta municipal. Essa horta (que se somava às hortas escolares) tinha a finalidade prioritária de abastecer as unidades escolares, e logo passou a ser aproveitada para 
atividades pedagógicas pelas escolas. Uma delas foi chamada de Projeto Mãos na Terra e o seu objetivo, segundo os idealizadores, era o de

desenvolver o amor do homem pela terra, pelo viés da agroecologia, efetivando ações práticas de plantio de chás, hortaliças, plantas condimentares e comestíveis em forma de mandalas, aliando à prática ao estudo da teoria, acionando o interesse nos adolescentes, da qualidade de vida melhor (Prefeitura, 2009).

Complementando esse projeto, outro foi realizado em conjunto com o Departamento de Meio Ambiente, chamado de Turismo Rural Pedagógico, no qual turmas de alunos realizavam aulas práticas em propriedades rurais do município. Com o objetivo de promover estilos de vida sustentáveis, integrando o homem à natureza, e desenvolver aprendizado ambiental focando na integração entre teoria e prática, procurou-se transformar a educação em algo situado e contextualizado. Assim, os alunos aprendiam na prática o que estavam estudando na teoria. Vários conceitos, cálculos, linguagens eram compreendidos quando se ligava a teoria da sala de aula com a prática vista nas propriedades rurais.

As atividades eram programadas semanalmente para que os alunos acompanhassem e participassem desde o preparo da terra (compostagem, minhocário) até a preparação culinária com o alimento produzido e a sua degustação.

A experiência evidenciou que, quando o aprendizado era temperado com emoções, vivências pessoais e atividade coletiva, os alunos ficavam mais interessados nos temas tratados em sala de aula. Os conceitos abstratos da matemática, da geografia e da história, por exemplo, se tornavam concretos e de mais fácil entendimento. Dessa forma, observou-se que, quando as crianças estavam inseridas na realidade, elas adquiriam habilidades críticas necessárias para julgar o contexto urbano e rural em que viviam e o que elas deveriam cuidar e valorizar. As novas experiências despertavam o interesse do aluno, que passava a ter vontade de saber mais.

Portanto, esse processo foi a base para a mudança conceitual e comportamental que se expressou em situações da vida prática, tanto nas escolhas e decisões pessoais quanto na participação em atividades cívicas. Segundo o depoimento dos pais desses alunos, embora a atividade tenha durado pouco tempo (um semestre), seus incentivos e a valorização das atividades rurais promoveram mudanças no comportamento dos filhos, que passaram a valorizar o agricultor e o meio rural e a consumir alimentos como legumes, hortaliças e outros produtos menos processados e a reproduzir as preparações que haviam aprendido em suas casas.

Outro ponto considerado nevrálgico para a mudança do ambiente e do comportamento alimentar dos alunos era a influência das cantinas escolares (ou venda de alimentos dentro da escola) e a circulação de alimentos não 
saudáveis trazidos de casa. Em relação às cantinas, não se permitia a venda de alimentos dentro da escola em nenhuma unidade de ensino municipal desde 1999. Os gestores públicos responsáveis pelo Programa de Alimentação Escolar se posicionavam contra a existência de bares nas escolas e limitaram, via normativa administrativa em 2008, os tipos de alimentos que poderiam ser enviados pelos pais para o lanche. Assim, guloseimas, salgadinhos, refrigerantes e alimentos com alta densidade energética eram proibidos, enquanto alimentos naturais e integrais eram incentivados. Essa intervenção, um tanto ou quanto compulsória, sobre os tipos de alimentos que circulam pela escola foi contestada por alguns, que considerarem a intervenção pública ditatorial, ferindo a liberdade de escolha dos indivíduos.

Segundo Morgan (2006), os dois principais mantras ideológicos da indústria de junk foods são: 1) não há alimentos ruins, mas dietas ruins; e 2) as escolhas alimentares são questões privadas e não públicas. Em relação à primeira questão, parece haver consciência dos gestores públicos de que existem alimentos ruins e que eles devem ser evitados. Morgan defende também que os altos custos para a saúde pública das doenças relacionadas à dieta amplificam a questão do ambiente das escolhas alimentares e põem em xeque a alegação de que o Estado estaria invadindo a vida privada ao regular essas escolhas. Dado que o público em pauta são crianças e que, cada vez mais, cresce a responsabilidade do Estado na provisão alimentar dessa população (que permanece nas escolas e creches por no mínimo quatro horas diárias, com tendência ascendente de público e de tempo), passa a ser questão de grande debate a divisão de responsabilidades entre o Estado e as famílias no desenho e desenvolvimento desses serviços públicos.

Dentro do marco legal e gerencial do PAE, portanto, não parece haver omissão do poder público em Dois Irmãos em relação às escolhas alimentares que são feitas para os alunos. Além das questões mencionadas, outro ponto a ser destacado nesta análise diz respeito aos critérios utilizados para compor o cardápio e, nesse quesito, enfatizam-se as preocupações nutricionais que têm como coadjuvantes a aceitação pelos escolares, distinguindo-se as preocupações com o hábito e a cultura alimentar e a valorização dos alimentos locais.

Essas intervenções podem ser vistas como efetivas no nível da mudança no comportamento alimentar a curto prazo e também a médio e longo prazos, visto não só atuarem como informativas para alterar hábitos, mas, principalmente, por agirem na própria construção de paladares e costumes. Não são estratégias educacionais pontuais, mas permanentes que, ao interagirem no nível do cognitivo, do prático, do corriqueiro, tornam práticas saudáveis em práticas comuns e não de adestramento ou de autocuidado e abnegação para se ter saúde. Ao contrário, as atividades buscam conjugar hedonismo aos hábitos favoráveis à saúde humana e ambiental, favorecendo o êxito das estratégias de educação alimentar. 
Segundo dados do próprio município, essas ações têm demonstrado efeitos positivos tanto na questão do consumo de alimentos mais saudáveis e naturais, como já referenciado, quanto no próprio estado nutricional. A vigilância em relação ao peso dos escolares entre 8 e 10 anos de idade realizada de 2003 até 2010 aponta para o aumento na proporção do número de escolares com peso adequado, ainda que de forma tímida (de 76,4\% em 2003 para 81,3\% em 2010). Mesmo que não se possa fazer inferência nem relação entre esses dados e as estratégias de promoção de consumo alimentar sustentável implantadas, pode-se considerar que são inovadoras e potencialmente eficazes no que se propõem. Não obstante, são proposições que merecem aprofundamento científico para serem atestadas.

Nesse sentido, pondera-se que a efetividade dos resultados pode ter sofrido algum prejuízo pela descontinuidade de alguns projetos e ações que dependiam de recursos financeiros e humanos. Além disso, também não se pode afirmar que as diversas ações realizadas no município foram idealizadas a priori e organizadas racionalmente de maneira coordenada. Muitas vezes ocorreu a pulverização de ações desarticuladas que só passaram a fazer sentido em certo momento e a partir da reunião de atores em locais comuns, como os conselhos gestores (nesse caso, teve importante papel o Conselho de Alimentação Escolar).

Diante disso, importa considerar que o esforço deste artigo foi no sentido de evidenciar experiências que merecem destaque por serem seminais, ao conjugar esforços de diversos atores, abordando o mesmo 'problema' de maneiras diversas, mas convergentes. Aponta-se, portanto, para a praticabilidade da questão intersetorial, multiprofissional e transdisciplinar de acordo com o marco de referência em educação alimentar e nutricional (Brasil, 2012). Assim, verifica-se, na sistematização das diversas ações realizadas em Dois Irmãos, que o município se antecipou à implantação de várias práticas previstas na lei n. 11.947, que só veio a ser sancionada em 2009.

\section{Considerações finais}

O contexto alimentar contemporâneo é constituído por interferências de estímulos midiáticos que incentivam o consumo de alimentos industrializados ou 'massificados'. Este estudo demonstra que é possível realizar educação alimentar e nutricional congregando-a à saúde e à sustentabilidade por meio da utilização de programa alimentar como o de alimentação escolar. Passa-se a enfatizar a seguinte pergunta: que tipo de ambiente alimentar e de valorações estamos propiciando aos nossos escolares? Contrapondo-se à tendência de desenraizamento alimentar, passa-se a valorizar a diferença, os valores 
culturais, tradicionais e locais, vislumbrando-se com isso a melhoria das condições nutricionais, sociais e ambientais.

Se cultivar a cultura alimentar é escolha reflexiva, é fato que, em Dois Irmãos, há atividades que configuram a necessidade de conjugá-la com aspectos de ordem nutricional, ambiental e socioeconômica. Enfatiza-se que os atores - gestores, profissionais de saúde, professores, cozinheiros etc. tornam-se agentes no sentido de serem reflexivos a ponto de agir em prol das mudanças políticas e culturais que acreditam ser necessárias.

Assim, dada a tendência de individualização das escolhas e das responsabilidades que se impõem sobre a população, dentro de cenário sem regras ou confuso, fazem-se necessários a conscientização e o discernimento principalmente das crianças. No caso específico, as pessoas envolvidas com essa mudança, em sua maioria, eram representantes do Estado, ressaltando-se a importância dessa instituição como interventora e reguladora sobre o consumo, alimentando nova forma de relação com a produção e o abastecimento de alimentos.

A institucionalização de novos modelos alimentares inclui não somente resultados que se mostrem positivos para os envolvidos, mas também a revisão das questões relacionadas às escolhas dos consumidores que baseiem sua confiança em regras relativas à proximidade e à tradição. Considerando a escola como espaço de socialização e multiplicação de valores, passam a ter relevância as valorações e os contextos normativos que ela providencia, influenciando nas ações e nos procedimentos dos escolares. Também é relevante a confluência de ações que se expandem para fora do domínio escolar e tomam corpo na sociedade e em outras secretarias e departamentos como os de saúde, educação, agricultura e meio ambiente. Nesse sentido, faz diferença o quanto as ações e as posturas dentro da mesma instância estatal (município) são inter-relacionadas ou se elas são dispersas e divergentes. Essas dinâmicas assinalam importantes estratégias as quais determinam movimentos que consolidam novas relações alimentares e que contestam/revertem a continuidade de tendências dominantes de consumo e produção.

A experiência em Dois Irmãos dá pistas do grande poder de influência do PAE na condução de modelos agroalimentares sustentáveis, tanto como mercado para os agricultores familiares quanto em seu papel interventor nas escolhas dos consumidores. Portanto, seria pertinente adicionar ao artigo 13 da lei n. 11.947/2009, que considera como

educação alimentar e nutricional o conjunto de ações formativas que objetivam estimular a adoção voluntária de práticas e escolhas alimentares saudáveis, que colaborem para a aprendizagem, o estado de saúde do escolar e a qualidade de vida do indivíduo (Brasil, 2009), 
que a EAN também deve conjugar ações que visem à sustentabilidade de nosso planeta. Afinal, ao escolher alimento, também estamos escolhendo modelo de desenvolvimento, e se ele não for sustentável, também não será saudável.

Resumen Este trabajo es sobre el consumo alimentario en el contexto de la alimentación escolar, entendiéndose este espacio como fuertemente propositivo en la formación de hábitos alimentarios saludables y de desarrollo sostenible. Relata el ejemplo del municipio de Dois Irmãos, en Río Grande do Sul, Brasil, y las acciones relativas al trabajo realizado con los escolares, conjugando cambios en el consumo y en la producción de alimentos y vinculando salud y sostenibilidad. Utilizando fuentes secundarias y observación participante. A partir de un diagnóstico preocupante sobre el estado alimentario y nutricional de esta población, se desarrollaron diversas actividades de promoción del consumo alimentario sostenible, entre ellas: revisión de los proveedores y de las cadenas de abastecimiento, de las formas de producción y de la calidad de los alimentos ofrecidos; regulación relativa al tipo de géneros traídos de casa; cuidado en la formulación de los menús; y desarrollo de actividades educativas prácticas que aúnan la mejora de los hábitos alimentarios y la valorización del medio rural. Se observaron, en este caso, ejemplos de prácticas innovadoras, desarrolladas en forma integrada, que articularon sinérgicamente educación alimentaria y nutricional con acciones para la consolidación de un sistema agroalimentario sostenible.

Palabras clave educación alimentaria y nutricional; consumo de alimentos; alimentación escolar; desarrollo; sostenibilidad. 


\section{Notas}

1 Universidade Federal da Fronteira Sul, Programa de Pós-Graduação em Agroecologia e Desenvolvimento Rural Sustentável, Curso de Nutrição, Realeza, Paraná, Brasil. <rozane.triches@uffs.edu.br>

Correspondência: Universidade Federal da Fronteira Sul, Campus Realeza, Rua Edmundo Gaievski, 1.000, CEP 85770-000, Realeza, Paraná, Brasil.

2 Estudo realizado a partir de dados e fontes secundárias coletadas para outros estudos: dissertação de mestrado com pesquisa submetida à aprovação de Comitê de Ética em Pesquisa do Hospital de Clínicas da Universidade Federal do Rio Grande do Sul e trabalho para o Grupo de Estudos e Pesquisas Agricultura Familiar e Desenvolvimento Rural (Gepad) e o Grupo de Pesquisa em Inovação, Poder e Desenvolvimento em Áreas Rurais do Brasil (Ipode). Para maiores detalhes sobre a metodologia, ver Triches e Giugliani, 2005, e Triches e Schneider, 2010. Não há conflito de interesses.

\section{Referências}

BOOG, Maria C. F. Contribuições da educação nutricional à construção da segurança alimentar. Saúde em Revista, Piracicaba, v. 1, n. 1, p. 17-23, 2004.

BRASIL. Lei n. 11.947, de 16 de junho de 2009. Dispõe sobre o atendimento da alimentação escolar e do Programa Dinheiro Direto na Escola aos alunos da educação básica. Diário Oficial da União, Brasília, seção 1, p. 2, 17 jun. 2009.

BRASIL. Ministério do Desenvolvimento Social e Combate à Fome. Marco de referência de educação alimentar e nutricional para as politicas públicas. Brasília: Secretaria Nacional de Segurança Alimentar e Nutricional, 2012.

BUSS, Paulo M. Promoção e educação em saúde no âmbito da Escola de Governo em Saúde da Escola Nacional de Saúde Pública. Cadernos de Saúde Pública, Rio de Janeiro, v. 15 n. 2, p. 177-185, 1999.
CANDEIAS, Nelly M. F. Conceitos de educação e de promoção em saúde: mudanças individuais e mudanças organizacionais. Revista de Saúde Pública, São Paulo, v. 31, n. 2, p. 209-213, 1997.

CERVATO-MANCUSO, Ana M.; VIEIRA, Viviane L.; COSTA, Christiane G. A. Alimentação como um direito humano e as políticas sociais atuais. In: DIEZ-GARCIA, Rosa W.; CERVATO-MANCUSO, Ana M. (org.). Mudanças alimentares e educação nutricional. Rio de Janeiro: Guanabara Koogan, 2011. p. 92-98.

CONTRERAS, Jesús H. Patrimônio e globalização: o caso das culturas alimentares. In: CANESQUI, Ana M.; DIEZ-GARCIA, Rosa W. Antropologia e nutrição: um diálogo possível. Rio de Janeiro: Editora Fiocruz, 2005. p. 129-146.

DIEZ-GARCIA, Rosa W. Publicidade e as práticas alimentares. In: DIEZ-GARCIA, Rosa W.; CERVATO-MANCUSO, Ana M. (org.). $\mathrm{Mu}$ - 
danças alimentares e educação nutricional. Rio de Janeiro: Guanabara Koogan, 2011. p. 128-135.

FREITAS, Jairo D.; PORTO, Marcelo F. Por uma epistemologia emancipatória da promoção da saúde. Trabalho, Educação e Saúde, Rio de Janeiro, v. 9, n. 2, p. 179-200, 2011.

INSTITUTO BRASILEIRO DE GEOGRAFIA E ESTATÍSTICA (IBGE). Produto Interno Bruto dos Municipios 2004-2008. Rio de Janeiro: IBGE, 2010.

INSTITUTO BRASILEIRO DE GEOGRAFIA E ESTATÍstICA (IBGE). Censo Populacional 2010. Rio de Janeiro: IBGE, 2011.

LANG, Tim; BARLING, David; CARAHER, Martin. Food Policy: Integrating Health, Environment and Society. Oxford: Oxford University Press, 2009.

LANG, Tim; HEASMAN, Michael. Food Wars: The Battle for Minds, Mouths and Markets. Londres: Earthscan, 2004.

MORGAN, Kevin. School Food and Public Domain: The Politics of the Public Plate. The Political Quarterly, Londres, v. 77, n. 3, p. 379-387, 2006.

MORGAN, Kevin; SONNINO, Roberta. Empowering Consumers: The Creative Procurement of School Meals in Italy and the UK. International Journal of Consumer Studies, v. 31, n. 1, p. 19-25, 2007.

MORGAN, Kevin; SONNINO, Roberta. The School Food Revolution: Public Food and the Challenge of Sustainable Development. Londres: Earthscan, 2008.
PREFEITURA (DOIS IRMÃOS). Rio Grande do Sul. Projeto Mãos na Terra. Dois Irmãos: Prefeitura, 2009.

SANTOS, Ligia A. S. Educação alimentar e nutricional no contexto da promoção de práticas alimentares saudáveis. Revista de Nutrição, Campinas, v. 18, n. 5, p. 681-692, 2005.

SANTOS, Ligia A. S. O fazer educação alimentar e nutricional: algumas contribuições para reflexão. Ciência e Saúde Coletiva, Rio de Janeiro, v. 17, n. 2, p. 453-462, 2012.

TRICHES, Rozane M.; GIUGLIANI, Elsa R. J. Obesidade, práticas alimentares e conhecimentos de nutrição em escolares. Revista de Saúde Pública, São Paulo, v. 39, n. 4 , p. 541-547, 2005.

TRICHES, Rozane M.; GIUGLIANI, Elsa R. J. Insatisfação corporal em escolares de dois municípios da região Sul do Brasil. Revista de Nutrição, Campinas, v. 20, n. 2, p. 119-128, 2007.

TRICHES, Rozane M.; SCHNEIDER, Sergio. Reconstruindo o elo perdido: a reconexão da produção e do consumo de alimentos através do Programa de Alimentação Escolar no município de Dois Irmãos (RS). Segurança Alimentar e Nutricional, Campinas, v. 17, n. 1, p. 1-15, 2010.

Recebido em 06/12/2012

Aprovado em 29/10/2014 